\title{
Perfil dos agricultores de uma cooperativa de Apodi/RN, receptividade ao cultivo de cártamo e percepção sobre agrotóxicos e alternativas
}

As mudanças climáticas impulsionam a busca por fontes sustentáveis ao desenvolvimento humano. Dentre elas está a substituição de combustíveis fósseis pelos oriundos de biomassa, como o biodiesel. O cártamo é uma planta com potencial de se tornar matéria-prima para produção desse combustível no semiárido nordestino, sendo interessante para a agricultura familiar, como impulso ao desenvolvimento socioeconômico local e regional. Objetivou-se verificar aceitabilidade de agricultores familiares de uma cooperativa de Apodi/RN quanto a essa possibilidade, apresentando cartilha com informações sobre o cultivo do cártamo em campo, bem como os tratos com a cultura. Diante da atual busca de cultivos mais sustentáveis, também se verificou a percepção dos agricultores sobre uso de defensivos agrícolas alternativos em substituição aos agrotóxicos. Para tanto, conduziram-se entrevistas semiestruturadas. Dentre os participantes desta pesquisa, percebeu-se a predominância de homens - 78\%, com $22 \%$ de mulheres - sendo ambos distribuídos majoritariamente na faixa etária dos 22 aos 59 anos ( $93 \%$ ). Dos entrevistados $80 \%$ são casados e a maioria reside na própria zona rural de Apodi (96\%). Quanto à escolaridade, a maior parte possui o Ensino Fundamental incompleto. Os participantes foram receptivos à cartilha e à possibilidade de cultivo, estando atualmente num cenário pouco diverso em culturas, frágil ante estiagens e pragas, apesar de considerarem que as espécies atuais oferecem boa lucratividade. Houve amplo reconhecimento da importância dos defensivos alternativos, principalmente justificados pela segurança à saúde.

Palavras-chave: Agricultura familiar; Carthamus tinctorius; semiárido.

\section{Characterization of farmers in a cooperative from Apodi/RN, receptivity to the safflower crop and perception on pesticides and alternatives}

\begin{abstract}
Climate changes urge a search for sustainable sources for human development. Among them, there is the fossil fuels replacement for biomass-originated ones, such as biodiesel. Safflower is a crop with potential to use as raw material for biodiesel in Brazilian northeastern semiarid region, being interesting for family farming, as a way to promote local socioeconomic development. It was aimed to verify if family farmers from a cooperative in Apodi, Rio Grande do Norte state, would accept this possibility, while presenting a booklet with information about safflower cultivation in the field, as well as dealing with the crop. According to the current search for more sustainable crops, the perception of farmers about the use of alternative pesticides instead of chemical ones was also verified. To this end, semi-structured interviews were conducted. Among the participants of this research, it was noticed the predominance of men - 78\%, with $22 \%$ of women - both being distributed mainly in the age group from 22 to 59 years old (93\%). Of those interviewed, $80 \%$ are married, and most live in Apodi's own rural area (96\%). As for education, most have incomplete elementary school. The participants were very receptive to this possibility, as currently being in a context of low crop diversity, which is a fragile condition under droughts and pests, although they classify current species as profitable. There was great acknowledgment of alternative pesticides importance, mostly justified by health safety.
\end{abstract}

Keywords: Family farming; Carthamus tinctorius; sustainability.

Topic: Desenvolvimento, Sustentabilidade e Meio Ambiente

Reviewed anonymously in the process of blind peer.

Emanuel Sousa

Universidade Federal do Rio Grande do Norte, Brasil http://orcid.org/0000-0003-3633-8217

\section{emanueu@gmail.com}

Raimunda Adlany Dias da Silva

Universidade Federal do Rio Grande do Norte, Brasil

http://lattes.cnpq.br/1816809780487274

http://orcid.org/0000-0002-2282-8883

adlanydias@gmail.com

Flávia Cunha de Morais (iD

Universidade Federal do Rio Grande do Norte, Brasil

http://lattes.cnpq.br/1604439047065708

http://orcid.org/0000-0002-6061-8692

flavinhamorais@gmail.com

6

DOI: 10.6008/CBPC2318-2881.2019.003.0004
Received: 20/09/2019

Approved: 10/11/2019
Émile Rocha de Lima (iD)

Universidade Federal do Rio Grande do Norte, Brasil

http://lattes.cnpq.br/9658828504533374

http://orcid.org/0000-0002-8596-1403

emilerochinha@gmail.com

Juliana Espada Lichston (10)

Universidade Federal do Rio Grande do Norte, Brasil

http://lattes.cnpq.br/0727435909982933

http://orcid.org/0000-0002-4042-4524

.lichston@gmail.com
Referencing this:

SOUSA, E.; SILVA, R. A. D.; MORAIS, F. C.; LIMA, É, R.; LICHSTON, J. E.. Perfil dos agricultores de uma cooperativa de Apodi/RN, receptividade ao cultivo de cártamo e percepção sobre agrotóxicos e alternativas. Nature and Conservation, v.12, n.3, p.25-36, 2019. DOI: http://doi.org/10.6008/CBPC2318-2881.2019.003.0004 


\section{INTRODUÇÃO}

O cenário de desenvolvimento socioeconômico no semiárido do nordeste brasileiro ainda hoje apresenta lentidão em seus avanços, perpetuando severos quadros de desigualdade social e degradação ambiental, está intensificada pelo agravamento das mudanças climáticas. A preocupação com as alterações de temperatura em função da ação antrópica tem levado cada vez mais à busca de alternativas sustentáveis para o desenvolvimento humano. Com a demanda energética constantemente aumentando e o conhecimento de que, além de grandes poluidores e emissores de gases de efeito estufa, os combustíveis fósseis apresentam reservas finitas, a atenção verte para soluções como os combustíveis provenientes de biomassa. Dentre esse grupo, destaca-se o biodiesel, que pode ser feito a partir de gordura animal ou vegetal, sendo as sementes de oleaginosas a principal fonte de matéria-prima.

Trata-se de alternativa vantajosa pela menor geração de poluentes (BARNWAL et al., 2005; LAPINSKIENE et al., 2007; HU et al., 2008), exequibilidade técnica, competitividade econômica, fácil disponibilidade e melhor aceitabilidade do ponto de vista ambiental (DEMIRBAS, 2009). Ele é seguro, biodegradável, renovável, atóxico e possui lubricidade inerente (AZAM et al., 2005; RASHID et al., 2008).

De acordo com Demirbas et al. (2007), a cadeia produtiva do biodiesel promove desenvolvimento regional e fortalece a estrutura social, principalmente em países em desenvolvimento. No Brasil, procura-se assegurar essa assertiva através do Programa Nacional de Produção e Uso do Biodiesel (PNPB), lançado pelo Governo Federal em 2004 e o Selo Combustível Social (BRASIL, 2011).

Para Peixoto (2008), o programa objetiva firmar um novo mercado para os agricultores familiares e assentados da reforma agrária, conciliando produção e meios de proteção ambiental. Para isso acontecer, destaca o autor, é necessário o esforço conjunto de instituições organizadas em rede, tais como: pesquisas agronômicas, tecnológicas e industriais; organização social da produção; associações e cooperativas de agricultores; empresas; organizações não governamentais, órgãos governamentais de fomento, regulamentação e fiscalização; representações de populações tradicionais; universidades, centros de pesquisa e outros órgãos gestores.

O enfoque regional é fundamental para o funcionamento do PNPB, de modo que a elaboração de projetos contemple as particularidades edafoclimáticas e sociais de cada localidade (PEIXOTO, 2008). É importante notar que as culturas vegetais precisam ser compatíveis com as condições locais para bom desenvolvimento e produtividade; por conseguinte, é necessária uma diversidade de espécies cultivadas, na qual se insere a relevância da investigação de novos potenciais para cada região.

O cártamo (Carthamus tinctorius L.) é uma planta promissora para cultivo voltado ao biodiesel no semiárido. Pertencente à família Asteraceae, a mesma do girassol - uma cultura mais tradicional nesse uso - ele é originário da Ásia e apresenta boa resistência ao estresse hídrico e salino, a temperaturas elevadas e frias, e à baixa umidade relativa do ar (EMONGOR, 2010). O ciclo de vida dura 140 dias, podendo ser encurtado a até 75 dias em temperaturas mais altas. Uma boa produção é observada com precipitações entre 300 a 600 mm anuais (ROCHA, 2005; VIVAS, 2002), compatível com o intervalo médio observado no 
semiárido, de 400 a 800 mm (NÓBREGA, 2001).

A espécie tem ainda várias possibilidades de valor agregado, o que pode ser bastante positivo para o agricultor familiar: nutrição animal (VIVAS, 2002), inclusive ração para aves (OLIVEIRA, 2016), corantes para alimentos e tecidos finos, uso medicinal (DAJUE et al., 1996; EMONGOR, 2010; HAN et al., 2009), ornamentação e uso do óleo em cápsulas para emagrecimento tem sido bastante popular.

A adoção de uma nova cultura, no entanto, requer diversos estudos para ser feita de forma responsável. Além de avaliar adaptação ao solo e ao clima, outro fator importante a se considerar é a suscetibilidade da espécie a patógenos e predadores locais. Na região Nordeste, o cártamo pode ser afetado por fungos do gênero Alternaria (FREIRE, 2009), que causa a doença da mancha foliar no girassol. Embora a reduzida umidade e elevada temperatura possa reduzir a incidência desse fungo no semiárido (ABBAS et al., 1995), é interessante trabalhar formas de prevenção e tratamento.

A proteção às lavouras frequentemente é feita com o uso de compostos químicos, os agrotóxicos, com o Brasil sendo um dos principais consumidores em todo o mundo desde 2008 (GRAFF, 2013). No entanto, sua adoção é incompatível com uma perspectiva de sustentabilidade, posto que podem representar grande risco ambiental e também serem prejudiciais à saúde do trabalhador (PERES et al., 2003). Ressalte-se também que o uso de agrotóxicos é regulado para cada cultura e doença pelo Ministério da Agricultura, Pecuária e Abastecimento, não havendo ainda algum registro para uso em cártamo.

Defensivos agrícolas alternativos buscam eliminar esse entrave, sendo uma solução mais segura e ambientalmente responsável, também não requerendo regulação legal, apesar de geralmente terem menor eficácia e persistência na lavoura, no caso dos orgânicos (e.g. à base de extratos vegetais), que são biodegradáveis (SCHMUTTERER, 1990).

Unindo todo o panorama aqui traçado está a figura do agricultor. É aquele que inicia a cadeia produtiva do biodiesel, é aquele a quem as políticas do PNPB se voltam para incentivar o desenvolvimento regional. Assim, a organização cooperativista torna-se uma forma de dar maior força aos pequenos produtores na inserção do mercado e na mobilização política. Ribeiro (2004) aponta a produção cooperativa como um desafio capaz de criar alternativas de trabalho e produção de renda, principalmente em um cenário social de desemprego, relações de trabalho desregulamentadas e perda de direitos constitucionais.

O agricultor se apresenta como um ator fundamental no processo de estabelecimento dessas políticas, mas que muitas vezes é excluído das pesquisas acadêmicas ou das discussões de gestão. $O$ fato é que a visão de mundo do agricultor deve ser levada em conta, principalmente por ser a realidade dele que será influenciada pela produção e aplicação do conhecimento científico. Com isso, o presente trabalho objetivou apresentar a cultura do cártamo a agricultores de uma cooperativa do município de Apodi-RN, e verificar a aceitabilidade quanto à sua possível introdução na região, como proposta para diversificação e crescimento da atividade agrícola local, na perspectiva de promover o desenvolvimento socioeconômico e ambientalmente sustentável. A pesquisa realizada ainda objetivou avaliar a percepção do grupo estudado quanto à prática do uso de agrotóxicos e defensivos agrícolas alternativos. 


\section{METODOLOGIA}

\section{Área de estudo}

Apodi é um município do oeste do estado do Rio Grande do Norte ( $5^{\circ} 39^{\prime} 51^{\prime \prime}$ S; $37^{\circ} 47^{\prime} 56^{\prime \prime}$ W), com uma área de 1.602,48 km² ocupada por 34.763 habitantes, sendo 17.376 homens e 17.387 mulheres (IBGE, 2010). Sua localização geográfica insere-o no clima semiárido, com temperatura média anual de $28,1^{\circ} \mathrm{C}$, precipitação pluviométrica anual de $717,9 \mathrm{~mm}$ (concentrada entre março e maio) e vegetação natural composta predominantemente pela caatinga hiperxerófila. O solo de maior parte da região apresenta restrições para a prática agrícola e pastagem animal, embora haja áreas favoráveis ao desenvolvimento de lavouras de ciclo curto (IDEMA, 2008).

\section{Caracterização do universo de pesquisa e amostragem}

A pesquisa foi realizada com agricultores de Apodi, associados à Cooperativa Potiguar de Apicultura e Desenvolvimento Rural Sustentável (COOPAPI), havendo um total de 222 cooperados. Utilizou-se amostragem não probabilística por acessibilidade, aproveitando a ocasião de reunião ordinária dos agricultores, a amostra consistiu em 45 pessoas, representando $20 \%$ do grupo total.

\section{Instrumento de coleta de dados}

A aquisição de informações sobre aceitação do cártamo e dinâmica dos agricultores filiados à Cooperativa Potiguar de Apicultura e Desenvolvimento Rural Sustentável (COOPAPI), se deu por meio da aplicação de um questionário semiestruturado, seguindo o método enquete, definido por Mekesenas (2002) como método em pesquisa empírica, que lida com grande número de informantes e faz uso de questionários organizado em partes, partindo das informações mais gerais para as mais específicas.

A caracterização das famílias se deu por meio de levantamento das seguintes informações: faixa etária, estado civil, quantidade de membros da família e grau de escolaridade, com finalidade de conhecer previamente o grupo compondo a primeira parte. A segunda parte do questionário foi composta por 12 questões - abertas e fechadas - contemplando o perfil atual da agricultura local, conhecimento e aceitabilidade da cultura do cártamo, incentivo governamental para a produção de biodiesel, e percepção quanto ao uso de agrotóxicos e soluções alternativas para controle de pragas e doenças. O questionário foi adaptado a partir do trabalho de Bezerra et al. (2011) e o discurso dos participantes, que assim o permitiram, foram gravados de modo a auxiliar a análise e possibilitar a transcrição de falas. Os dados obtidos foram tabulados em termos percentuais, o que consistiu na base para análise, associada à percepção dos pesquisadores quanto ao discurso dos entrevistados.

\section{Material de divulgação}

Uma cartilha foi produzida para distribuição entre os agricultores após as entrevistas, com informações gerais a respeito do cártamo, incluindo seus potenciais usos econômicos de acordo com a 
literatura, bem como resultados e observações de pesquisas experimentais com a espécie, realizadas pelo Laboratório de Investigação de Matrizes Vegetais Energéticas da Universidade Federal do Rio Grande do Norte (LIMVE-UFRN), em parceria com a Escola Agrícola de Jundiaí (EAJ-UFRN) e o Instituto Federal de Educação, Ciência e Tecnologia do Rio Grande do Norte (IFRN-Campus Apodi).

Para possuir ampla acessibilidade, o material tem linguagem simples, com texto curto e amplamente ilustrado, funcionando como uma introdução geral ao tema e uma ponte de contato com os pesquisadores. Em conjunto com a cartilha, amostras de grãos de cártamo foram fornecidas para conhecimento dos agricultores, considerando que a espécie atualmente não possui tradição de cultivo na região.

\section{RESULTADOS E DISCUSSÃO}

\section{Perfil dos agricultores}

Na amostra acessada por esta pesquisa, houve predominância de homens $-78 \%$, com $22 \%$ de mulheres - sendo ambos distribuídos majoritariamente na faixa etária dos 22 aos 59 anos (93\%). 80\% dos entrevistados são casados, e a maioria reside na própria zona rural de Apodi (96\%). Quanto à escolaridade, a maior parte possui o Ensino Fundamental incompleto (geralmente tendo cursado até a 4a série), seguidos de $18 \%$ que declararam não serem alfabetizados, $13 \%$ com Ensino Médio completo, $11 \%$ com o Fundamental completo, 9\% com o Médio incompleto e, por fim, uma pessoa com nível Superior incompleto e uma com Graduação completa. Os dados de perfil foram sumarizados na Figura 1.

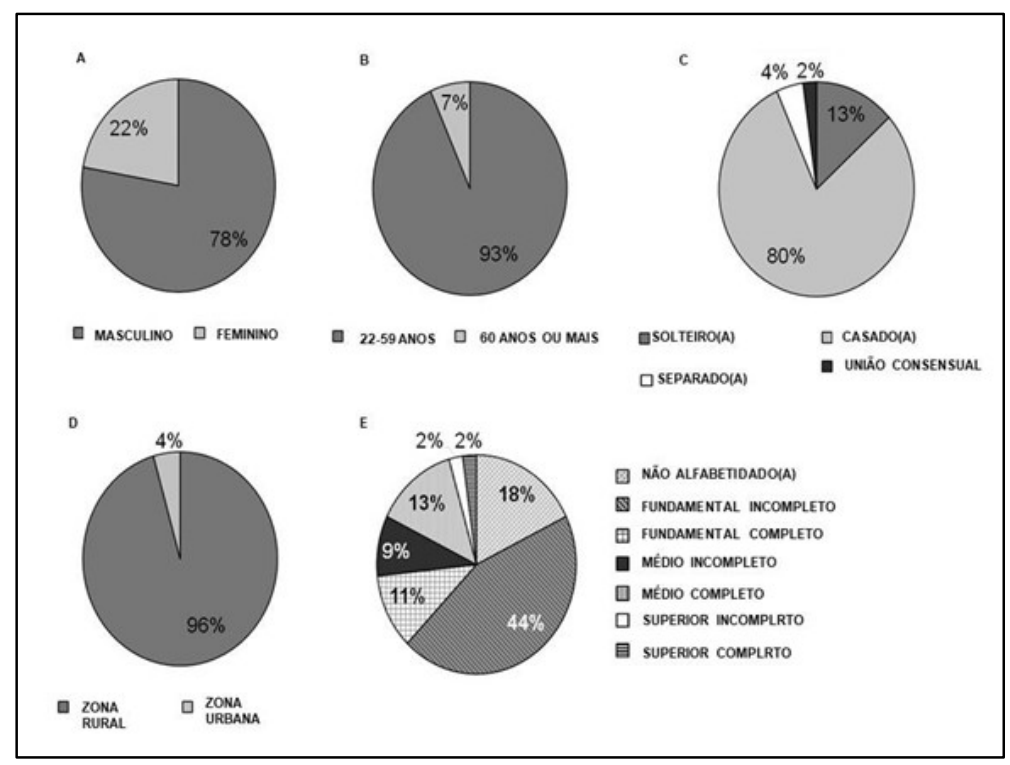

Figura 1: Perfil dos agricultores familiares entrevistados da Cooperativa de Potiguar de Apicultura e Desenvolvimento Rural Sustentável (COOPAPI). A: gênero, B: idade, C: estado civil, D: local de residência; E: escolaridade.

\section{Plantas cultivadas e recursos necessários a novas culturas}

A mais viável fonte de renda agrícola citada foi o cajueiro - lembrado por $71 \%$ dos entrevistados sendo uma das culturas mais características do RN, que disputa o segundo lugar na produção nacional de castanha (IBGE, 2017; IBGE, 2014). Recentemente, o caju (pedúnculo carnoso reconhecido como fruta), antes frequentemente desprezado, também vem ganhando importância econômica. 
A escassez pluviométrica na região nos últimos anos têm intensificado, além da deficiência hídrica (GOIS, 2014), a proliferação da mosca branca, praga que afeta o cajueiro e constitui perigosa ameaça à produção (SILVA et al., 2008). Esse momento de fragilização econômica evidencia a importância de se firmar alternativas de renda viáveis, reduzindo prejuízos. A grande maioria dos agricultores entrevistados (96\%) afirma que já sofreu grandes perdas no passado em função de períodos prolongados de estiagem.

À parte do viés comercial, o feijão foi a cultura mais lembrada pelos entrevistados (96\%). Diferente do caju, destina-se primariamente à subsistência. A espécie cultivada é o feijão macáçar, Vigna unguiculata (L.) Walp, tradicionalmente a base da alimentação sertaneja. A estabilidade de rendimento da espécie sob condições de estresse abiótico (temperaturas elevadas e pouca chuva) e a baixa necessidade de intervenção durante o período vegetativo (LOBATO et al., 2009), justificam sua adoção. Segundo F., 34 anos, 'o pessoal prefere algo que seja só jogar e colher'. Milho e sorgo concluem a lista de culturas mais citadas, com 64\% e $53 \%$, respectivamente. Culturas menos lembradas foram mencionadas como tendo escala de produção pequena: hortaliças e frutas (com maior destaque para a melancia), macaxeira, capim, carnaúba (Figura 2A).

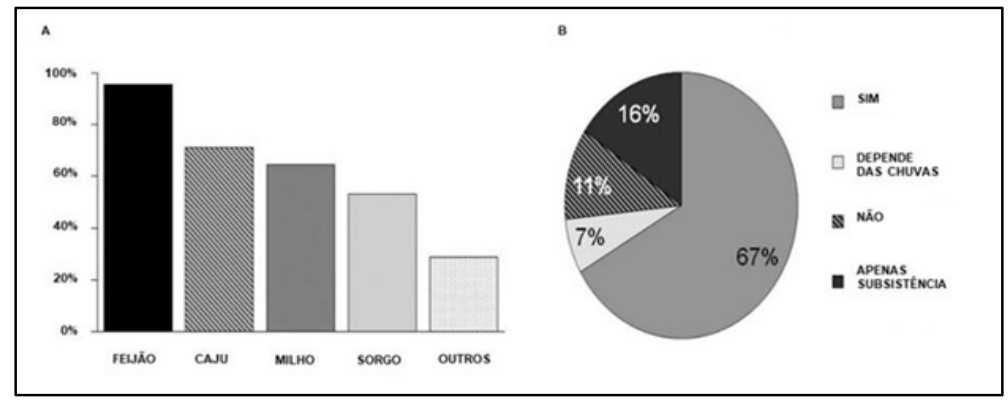

Figura 2: Perfil e perspectiva do estado atual da agricultura na região. A: Menções a culturas produzidas pelos agricultores da COOPAPI. B: percepção de rentabilidade das culturas produzidas.

Com baixa diversidade de espécies cultivadas, relacionada às dificuldades encontradas, é compreensível que os agricultores sejam bem receptivos à perspectiva de novas culturas - mesmo que a maioria das pessoas tenha respondido que as atuais oferecem boas lucratividade e condições dignas de sobrevivência (Figura 2-B) - considerando que haja assistência técnica para ensinar os tratos de cultivo. Quase todos os agricultores entrevistados (98\%) estariam dispostos a plantar novas espécies em suas propriedades. A única pessoa que afirmou não ter interesse acredita não haver outra cultura que consiga se estabelecer nas condições da região.

Evidentemente, não é necessário apenas vontade; o estabelecimento de uma nova cultura é dependente de recursos. A água foi a mais lembrada (47\%), o que é condizente com as dificuldades anteriormente expostas. A maioria lembrou desse recurso na forma pluvial, citando a necessidade de um bom inverno (referência ao período chuvoso). Nota-se, pois, que as menções se aproximam da realidade corrente dos participantes. A irrigação, que permitiria distribuição constante e regulável de água, foi lembrada por poucos.

Cerca de $16 \%$ dos entrevistados afirmaram que é preciso a cultura ser adaptada às condições da região, ou seja, tolerante ao clima, condições do solo e escassez de água, com ciclo de vida curto, compatível 
com o período de chuvas. Fatores que não impedem o cultivo do cártamo na região, pois trata-se de uma espécie resistente às condições ambientais características do semiárido (PUREY et al., 2008). Outros 16\% remetem à importância de projetos e de incentivo governamental para viabilizar o cultivo. Para 9\%, é preciso um bom solo ou adubação adequada.

A necessidade de compradores ou indústria para o produto foi lembrada por $9 \%$ dos agricultores, uma preocupação muito válida: em anos anteriores, houve incentivo por parte do governo para o cultivo de mamona para biodiesel no nordeste. A espécie nunca alcançou boa rentabilidade para os agricultores. $7 \%$ dos entrevistados mencionaram a importância da própria capacitação ou conhecimento sobre a cultura. Outras menções incluem a atratividade para abelhas (posto que a cooperativa desenvolve atividade apicultora), adequação a consórcio e rotação de culturas e instrumentos/maquinário adequados ao manejo. $11 \%$ dos participantes não souberam responder (Figura 3).

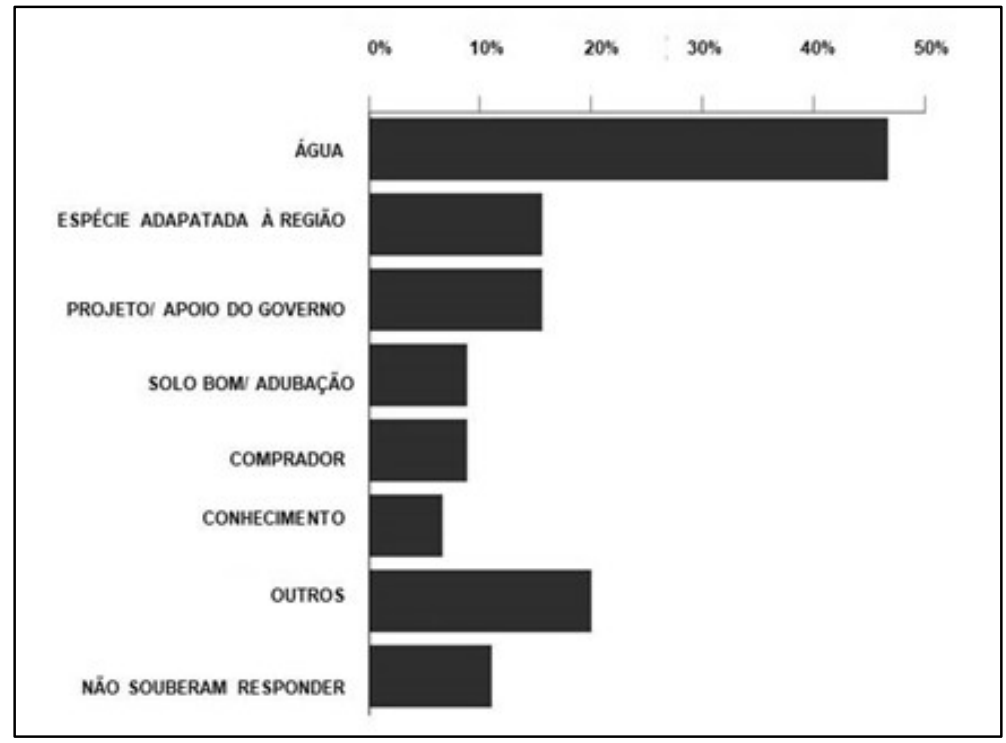

Figura 3: Recursos citados pelos agricultores como necessários para o estabelecimento de uma nova cultura no semiárido.

\section{Potencial do cártamo}

Quando perguntados se já haviam ouvido falar em cártamo, 84\% afirmaram que não (Figura 4-A). A espécie não é vastamente difundida no Brasil, tendo maior ocorrência no sul do país. Os $16 \%$ que reconheceram o nome podem ser justificados pela veiculação de produtos na TV (anúncios de cápsulas à base de óleo de cártamo, vendidas como alternativas para auxiliar o emagrecimento), e pelos experimentos conduzidos no campus do IFRN que fica no município de Apodi - um dos entrevistados disse que sua filha frequentava o curso técnico em biocombustíveis oferecido pela instituição.

Além do potencial para biodiesel pelo qual está sendo estudado, foram citados para os participantes outros potenciais usos do cártamo documentados na literatura (EMONGOR, 2010), e em seguida questionado se haveria perspectiva de lucratividade com a espécie. $84 \%$ acredita que sim, $2 \%$ não e $13 \%$ comentaram que apenas saberiam responder se testassem a cultura previamente (Figura 4-B). Ressalta-se aqui a importância da pesquisa de viabilidade e manejo adequado do cártamo na região, pois de fato uma 
resposta concreta somente pode ser obtida com esses dados. No entanto, a predisposição do agricultor a adotar a cultura é fundamental, sendo importante verificar sua opinião em um momento preliminar como o aqui documentado.

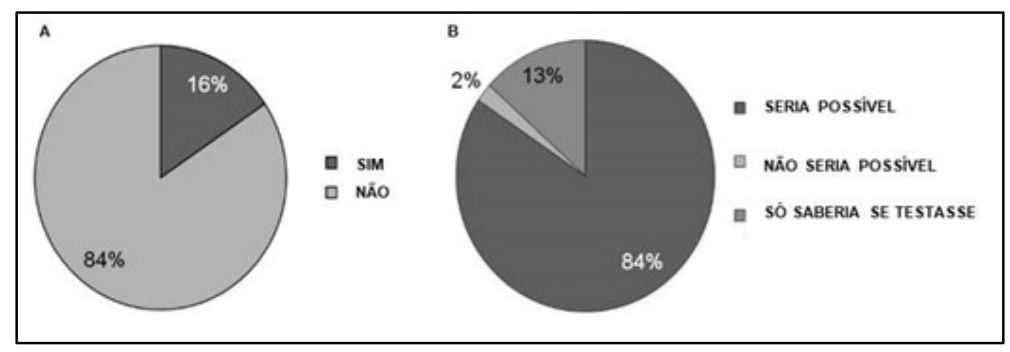

Figura 4: Conhecimento prévio e perspectiva dos agricultores quanto à cultura do cártamo. A: conhecimento prévio sobre a espécie. B: perspectiva de lucratividade ante o potencial apresentado.

\section{Biodiesel}

O cultivo de espécies vegetais oleaginosas para produção de biodiesel não é prática presentemente difundida entre os agricultores da COOPAPI. Somente $18 \%$ dos participantes afirmaram ter alguma experiência com espécies como girassol e mamona (Figura 5-A), não obtendo resultados satisfatórios. Além das já conhecidas dificuldades de ordem natural, a falta de informação e incentivo na região podem ser apontados para a incipiência da prática. Dentre os entrevistados, $71 \%$ desconhecem o Programa Nacional de Produção e Uso do Biodiesel (PNPB), desenvolvido pelo Governo Federal e que inclui em suas metas a inserção da agricultura familiar na cadeia produtiva do combustível como via de desenvolvimento socioeconômico (ABRAMOVAY et al., 2007). 20\% ouviram falar do programa por rádio ou televisão, mas desconhecem detalhes, $7 \%$ afirmam conhecer e avaliam positivamente, enquanto para $2 \%$ a avaliação é negativa (Figura 5-B). Para 93\% dos participantes desta pesquisa, o cultivo de cártamo para produção de biodiesel traria perspectiva de melhorias para a região (Figura 5-C). Isso reforça novamente a receptividade dos produtores locais e a grande necessidade do acompanhamento técnico e investimento financeiro.

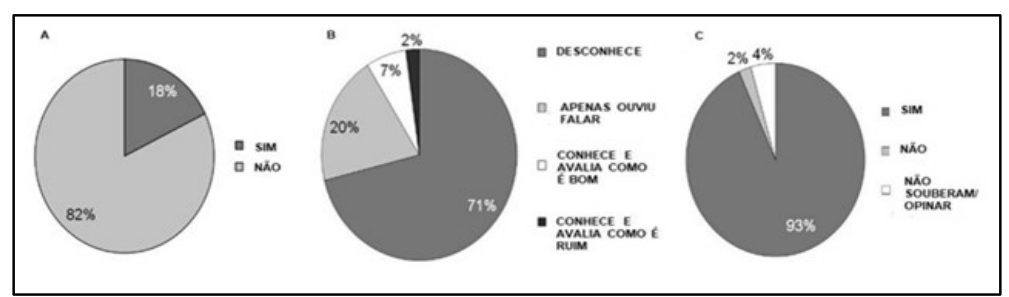

Figura 5: Relação e perspectivas dos agricultores da COOPAPI sobre a produção de culturas para biodiesel. A: experiência prévia com oleaginosas para biodiesel. B: conhecimento prévio sobre o Programa Nacional de Produção e Uso do Biodiesel (PNPB). C: perspectiva de melhorias para a região cultivando cártamo para biodiesel.

\section{Percepção da importância de defensivos agrícolas orgânicos}

Embora não tenha sido lembrado por nenhum participante durante o questionamento sobre recursos necessários a uma nova cultura, é importante que se estabeleçam formas de prevenção e tratamento adequados ao ataque de insetos e doenças. Agrotóxicos são uma via de escolha comum, mas seu uso não deve ser indiscriminado, dados os riscos para a saúde do trabalhador e para o meio ambiente (PERES et al., 2003). 
Muitos dos agricultores não costumam usar qualquer forma de prevenção ou controle de pragas e patologias em suas lavouras. Dentre os entrevistados, $47 \%$ já fizeram uso de tratamentos com produtos alternativos. Essa taxa considerável se deve à capacitação por meio de cursos ministrados na cooperativa, que têm incentivado o uso de extrato (vegetal) de nim (Azadirachta indica A. Juss.) e urina bovina.

Mesmo dentre os que nunca usaram um produto dessa natureza, há reconhecimento de seu valor: $80 \%$ do total acreditam que é importante optar por produtos orgânicos, mesmo que requeiram maior esforço de aplicação - por serem biodegradáveis, compostos desse tipo possuem baixa persistência no ambiente e logo perdem eficácia (SCHMUTTERER, 1990) - e em geral não sejam tão eficientes quanto formulações químicas comerciais. A preocupação com a saúde é unânime, enquanto menções ao risco ambiental foram mais escassas. Algumas pessoas também consideraram que os químicos adoecem as plantas cultivadas; essa afirmação pode ser verdadeira em alguns casos, pois há substâncias que podem afetar negativamente o processo de fotossíntese do vegetal (PETIT et al., 2012). 16\% acreditam que, seguindo as instruções corretamente, é possível usar agrotóxicos sem grandes problemas, quando necessário (Figura 6). Para alguns deles, o 'veneno' é mais acessível e barato, justificando a escolha.

Para F., 34 anos, o uso de agrotóxico resulta da falta de apoio técnico, que promoveria manejo adequado e asseguraria boa produção de forma orgânica. Ele alega que o crescente uso de químicos tem provocado aumento de casos de câncer, assertiva que é corroborada por estudos científicos (PARRÓN et al., 2014; PEREIRA et al., 2010). Ainda segundo ele, sabendo plantar e colher nos períodos adequados não é necessário fazer aplicação de nenhum tipo de produto.

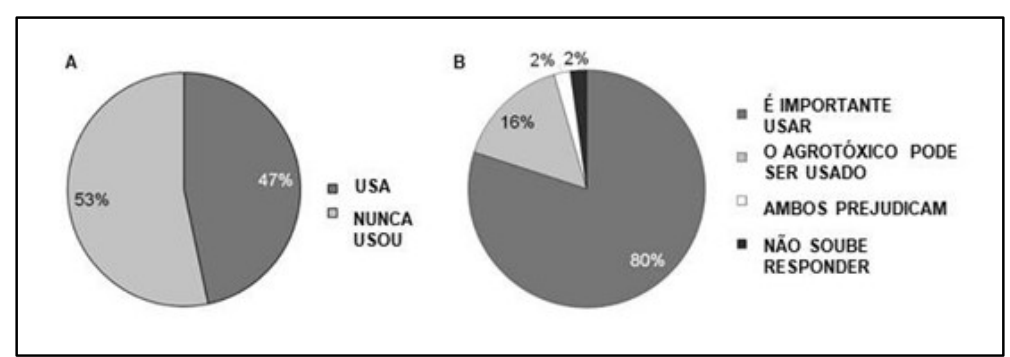

Figura 6: Percepção e prática de uso de defensivos agrícolas alternativos a agrotóxicos. A: uso de defensivos orgânicos. B: Percepção da importância do uso de orgânicos.

J., 44 anos, adepta ao uso do extrato de nim e urina de vaca, afirma que 'trabalhar com o químico é para quem não tem paciência'. 'Usar o orgânico é praticar o bem para si e para o próximo'. Ela demonstra consciência dos problemas ambientais e reforça bastante os benefícios à saúde, alegando ser alérgica aos químicos. M., 48 anos, argumenta: 'se você vai produzir uma coisa pra você comer, você não vai botar o veneno', indicando que os produtos comercializados convencionalmente em supermercados são todos tratados com agrotóxicos - uma preocupante verdade, com parte considerável dos alimentos contendo níveis de resíduo acima do máximo recomendado (ANVISA, 2013). Por preferir não usar esse tipo de substância, ele afirma que sua produção de castanha na última safra foi reduzida, mas que prefere essa escolha. 'Não gosto de mexer em veneno, me ataca logo a cabeça...'. Para S., 63, 'o orgânico é bom pra tudo, já o químico faz mal pra toda a humanidade da terra'. 


\section{Recepção à cartilha de divulgação}

A cartilha de divulgação produzida para este trabalho e entregue após cada entrevista foi bastante chamativa para os agricultores. Alguns deles foram atraídos ao perceber a entrega do material, e então foram convidados a responder às questões. Contudo, ele não foi produzido com a intenção de angariar participantes para a pesquisa, mas de promover a divulgação das características e potencial da espécie (que, com efeito, era desconhecida da maioria) e dos trabalhos experimentais desenvolvidos pelos pesquisadores e seus colaboradores.

A idealização desse material advém da compreensão de que a informação e o conhecimento não são vias unilaterais, de modo que o papel da população consultada não deve ser meramente o de fonte de dados para os pesquisadores, mas que também destes receba algum benefício. É preciso haver bilateridade entre ciência e sociedade em uma prática interdisciplinar que está aliada ao desenvolvimento socioeconômico com responsabilidade ambiental.

Com seus dados gerais, sem um aprofundamento que não seria apropriado ao formato e momento, a cartilha deve ser encarada como passo inicial para esse tipo de relação, fomentando o interesse para experiências posteriores. Os resultados obtidos com a presente pesquisa incentivam o desenvolvimento de mais estudos no campo experimental, validando o esforço da pesquisa científica em favor do desenvolvimento sustentável, pautado na tríade sociedade-meio ambiente-economia.

\section{CONCLUSÕES}

Embora em geral os agricultores da COOPAPI acreditem que as culturas produzidas atualmente por eles sejam suficientes para boas condições de sobrevivência, nota-se que o discurso sobre lucratividade pesa fortemente apenas para a cajucultura. Com as condições climáticas da região frequentemente prejudicando a produção, em meio a estiagens e pragas como a mosca branca, a diversificação de fontes de renda a partir de novas culturas torna-se uma perspectiva interessante para reduzir o potencial de prejuízos e gerar valor agregado, que pode ajudar a elevar o patamar socioeconômico local. Com isso, a aceitação do cártamo, mesmo sendo uma espécie pouco conhecida na região, foi muito positiva.

O material distribuído se mostrou eficiente na divulgação da espécie, contribuindo com a elucidação do método de cultivo e importância econômica. No tocante ao uso de agrotóxicos e soluções alternativas, fica evidente no senso comum a associação dos 'venenos' com prejuízos à saúde. Há ainda que se despertar a consciência para os prejuízos ambientais, de modo a inibir mais amplamente o consumo de agrotóxicos e estimular o uso de produtos seguros.

Para aprofundamento nos temas, recomendam-se mais estudos de consulta popular, abordando outras populações rurais do semiárido, como agricultores não cooperados ou associados - estes, com menor coesão e força política, podem ter visão diferenciada ante suas próprias dificuldades. Também é preciso avaliar os elos seguintes da cadeia produtiva de biodiesel, de modo a conhecer o interesse da indústria e do governo em negociar a aquisição de matéria-prima dos agricultores familiares da região. 
AGRADECIMENTOS: ao Ministério de Ciência, Tecnologia, Inovações e Comunicações; à EAJ-UFRN; ao IFRN-

Apodi pela parceria nas pesquisas experimentais.

\section{REFERÊNCIAS}

ABBAS, H. K.; EGLEY, G. H.; PAUL, R. N.. Effect of conidia production temperature on germination and inefectivity of Alternaria helianthi. Phytopathology, v.85, n.6, p.667-682, 1995.

ABRAMOVAY, R.; MAGALHÃES, R.. O acesso dos agricultores familiares aos Mercados de Biodiesel: parceria entre grandes empresas e movimentos sociais. In: CONFERÊNCIA DA ASSOCIAÇÃO INTERNACIONAL DE ECONOMIA ALIMENTAR E AGROINDUSTRIAL. Anais. Londrina, 2007.

ANVISA. Agência Nacional de Vigilância Sanitária. Programa de Análise de Resíduos de Agrotóxicos em Alimentos (PARA): relatório de atividades de 2011 e 2012. Brasília: ANVISA, 2013.

AZAM, M. M.; WARIS, A.; NAHAR, N. M.. Prospects and potential of fatty acid methyl esters of some non-traditional seed oils for use as biodiesel in India. Biomass and bioenergy, v.29, n.4, p.239-302, 2005. DOI: http://doi.org/10.1016/j.biombioe.2005.05.001

BARNWAL, B. K.; SHARMA, M. P.. Prospects of biodiesel production from vegetable oils in India. Renewable and Sustainable Energy Reviews, v.9, p.363-378, 2005. DOI: http://doi.org/10.1016/j.rser.2004.05.007

BEZERRA, P. D. F.; LICHSTON, J. E.; CÂNDIDO, G.

A.. Conhecimento e possibilidade de aceitação do cultivo de faveleira (Cnidoscolos quescifolius Pohl) por agricultores cooperados de Apodi/RN. In: FREIRE, M. E. X.; CÂNDIDO, G. A.; AZEVEDO, P. V.. Múltiplos olhares sobre o semiárido brasileiro: perspectivas interdisciplinares. Natal: EDUFRN, 2011. p.95-114.

BRASIL. Biodiesel: Selo Combustível Social. 2011.

DAJUE, L.; MÜNDEL, H.. Safflower: Carthamus tinctorius L. Roma: International Plant Genetic Resources Institute, Gatersleben, 1996.

DEMIRBAS, A. H.; DEMIRBAS, I.. Importance of rural bioenergy for developing countries. Energy Conversion and Management, v.48, p.2386-2398, 2007. DOI: http://doi.org/10.1016/j.enconman.2007.03.005

DEMIRBAS, A.. Progress and recent trends in biodiesel fuels. Energy Conversion and Management, v.50, p.14-34, 2009. DOI: http://doi.org/10.1016/j.enconman.2008.09.001

EMONGOR, V.. Safflower (Carthamus tinctorius L) the underutilized and neglected crop: a review. Asian Journal of Plant Sciences, v.9, n.6, p.299-306, 2010.

FREIRE, F. C. O.. Alternaria helianthi associada a folhas de cártamo no estado do Ceará. Fortaleza: Embrapa Agroindústria Tropical, 2009.
GOIS, K.. Seca paralisa produção de castanha caju em Apodi. 2014.

GRAFF, L.. Os agrotóxicos e o meio ambiente: uma abordagem a partir do direito humano à alimentação adequada. Dissertação (Mestrado em Direito Ambiental) Universidade de Caxias do Sul, Caxias do Sul, 2013.

HAN, X.; CHENG, L.; ZHANG R.; B. I, J.. Extraction of safflower seed oil by supercritical $\mathrm{CO}_{2}$. Journal of food engineering, v.92, p.370-376, 2009. DOI: http://doi.org/10.1016/j.jfoodeng.2008.12.002

HU, Z.; TAN, P; YAN, X.; LOU, D.. Life cycle energy, environment and economic assessment of soybean-based biodiesel as an alternative automotive fuel in China. Energy, v. 33, p. $1654-1658,2008$. DOI: http://doi.org/10.1016/j.energy.2008.06.004

IBGE. Instituto Brasileiro de Geografia e Estatística. Cidades: Apodi. Rio de Janeiro: IBGE, 2010.

IBGE. Instituto Brasileiro de Geografia e Estatística. Levantamento Sistemático da Produção Agrícola: Pesquisa Mensal de Previsão e Acompanhamento das Safras Agrícolas no Ano Civil. Rio de Janeiro: IBGE, 2017.

IBGE. Instituto Brasileiro de Geografia e Estatística. Levantamento Sistemático da Produção Agrícola. Rio de Janeiro: IBGE, 2014.

LAPINSKIENE, A.; MARTINKUS, P.; VILIJA, R.. Eco-toxicological studies of diesel and biodiesel fuels in aerated soil, Environmental Pollution, v.142, p.432-437, 2006. DOI: http://doi.org/10.1016/j.envpol.2005.10.023

LOBATO, A. K. S.; SANTOS, F.; COSTA, R. C. L.; GONÇALVESVIDIGAL, M. C.; MORAES, E. C.; OLIVEIRA, N.; BARRETO, A. G. T.. Morphological, physiological and biochemical responses during germination the cowpea (Vigna unguiculata CV. Pitiuba) seeds under salt stress. World Journal of Agricultural Science, v.5, n.5, p.590-596, 2009.

NÓBREGA, S. B. P.. Caracterização da faveleira (Cnidoscolus quercifolius) como fonte alternativa na alimentação humana e animal, no semi-árido paraibano. Dissertação (Mestrado em desenvolvimento e meio ambiente) Universidade Federal da Paraíba, João Pessoa, 2001.

MEKESENAS, P.. Pesquisa social e ação pedagógica conceitos, métodos e práticas. São Paulo: Loyola, 2002.

OLIVEIRA, C. V. K.. Análise do cártamo como cultura enérgica. Dissertação (Mestrado em Energia na Agricultura) Universidade Estadual do Oeste do Paraná, Cascavel, 2016.

PARRÓN, T.; REQUENA, M.; HERNÁNDEZ, A. F.; ALARCÓN, R.. Environmental exposure to pesticides and cancer risk in 
multiple human organ systems. Toxicol Lett, v.230, n.2, p.157-165, 2014. DOI:

http://doi.org/10.1016/i.toxlet.2013.11.009

PEIXOTO, R. C. D.. A rede paraense de agricultura familiar e biodiesel. Boletim do Museu Paraense Emílio Goeldi, v.3, n. 3,2008

PEREIRA, A. E.; SANTOS, N. D.; FRACETO, L. F.; LIMA, R. D.. Análise citogenética em trabalhadores rurais expostos a agrotóxicos. Bioikos, v.24, n.1, p.57-62, 2010.

PERES, F.; MOREIRA, J. C.; DUBOIS, G. S.. Agrotóxicos, saúde e ambiente: uma introdução ao tema. In: PERES, F.; MOREIRA, J. C. É veneno ou é remédio? Agrotóxicos, saúde e ambiente. Manguinhos: Fiocruz, 2003. p.23-24.

PETIT, A. N.; FONTAINE, F.; VATSA, P.; CLÉMENT, C.. Fungicide impacts on photosynthesis in crop plants. Photosynthesis Research, v.111, n.3, p.315--326, 2012.

PUREY, S.; SHARMA, N. C.. Safflower-An Ancient Wonderful Crop. In: MUKHERJE, S. P.. Everyman's Science. 3 ed. 2018.

RASHID, U.; ANWAR, F.; MOSER, B. R.; KNOTHE, G.. Moringa oleifera oil: A possible source of biodiesel. Bioresource Technology, v.99, p.8175-8179, 2008. DOI: http://doi.org/10.1016/j.biortech.2008.03.066
RIBEIRO, M.. Organizações cooperativas de agricultores e educação escolar: desafios a uma formação cooperativa. Perspectiva, v.22, n.1, p.167-194, 2004.

IDEMA. Instituto de Desenvolvimento Sustentável e Meio Ambiente. Perfil do seu município: Apodi. Natal: IDEMA, 2008.

ROCHA, E. K. Fenologia e qualidade de Carthamus tinctorius L. em diferentes populações e épocas de cultivo.

Dissertação (Mestrado em agronomia) - Universidade Federal de Santa Maria, Santa Maria, 2005.

SCHMUTTERER, H.. Properties and potential of natural pesticides from the neem tree, Azadirachta indica. Annual Review of Entomology, v.35, p.271-297, 1990.

SILVA, P. H. S.; CARNEIRO, J. S.; CASTRO, M. J. P.. Manejo da mosca-branca-do-cajueiro com óleos vegetais. Teresina: Embrapa Meio-norte, 2008.

STOILOVA, T.; PEREIRA, G.; SOUSA, M. T.. Evaluation of cowpea germplasm collection as a source of initial material for breeding. Journal of Central European Agriculture, v.14, n.3, p.854-864, 2013.

VIVAS, M. J.. Culturas alternativas: cártamo, sésamo e camelina. Melhoramento, v.38, p.183-192, 2002.

A CBPC - Companhia Brasileira de Produção Científica (CNPJ: 11.221.422/0001-03) detém os direitos materiais desta publicação. Os direitos referem-se à publicação do trabalho em qualquer parte do mundo, incluindo os direitos às renovações, expansões e disseminações da contribuição, bem como outros direitos subsidiários. Todos os trabalhos publicados eletronicamente poderão posteriormente ser publicados em coletâneas impressas sob coordenação da Sustenere Publishing, da Companhia Brasileira de Produção Científica e seus parceiros autorizados. Os (as) autores (as) preservam os direitos autorais, mas não têm permissão para a publicação da contribuição em outro meio, impresso ou digital, em português ou em tradução. 